Recepción: 27 / 05 / 2018

Aceptación: 01 / 06 / 2018

\title{
Programa creciendo con nuestros hijos para estimular el lenguaje: Ventajas y desventajas
}

\author{
Growing with our children program to stimulate language: advantages and \\ disadvantages
}

\author{
Verónica Mayorga ${ }^{\mathrm{I}}$ \\ Universidad Técnica de Ambato \\ Ambato; Ecuador \\ va.mayorga@uta.edu.ec \\ Mauricio Salas II \\ Universidad Técnica de Ambato \\ Ambato; Ecuador \\ ingmauriciosalas@hotmail.com \\ Verónica Llerena ${ }^{\text {III }}$ \\ Universidad Técnica de Ambato \\ Ambato; Ecuador \\ veronicadllerena@uta.edu.ec
}

Correspondencia: va.mayorga@uta.edu.ec

Docente; Universidad Técnica de Ambato.

Docente; Universidad Técnica de Ambato.

Docente; Universidad Técnica de Ambato. 


\section{Resumen}

Creciendo con Nuestros Hijos - CNH constituye un programa social impulsado por el gobierno central dirigido a familias de niños y niñas entre 0 a 36 meses con el objetivo de que este grupo de infantes desarrollen acciones educativas de calidad, es decir lograr un desarrollo socio afectivo, motor, intelectual, de la comunicación y lenguaje favoreciendo un adecuado estado de salud y nutrición. Esta actividad, es desarrollada por educadoras y educadores profesionales conjuntamente con el apoyo de las familias buscando promover el desarrollo integral desde las edades más tempranas, a través de formas organizativas y de dirección de todas las actividades con la finalidad de propiciar estímulos al máximo de todas las potencialidades de los infantes y garantizar un sano crecimiento. Por otro lado, el lenguaje constituye un proceso paulatino en el que el infante procesa gracias a las continuas interacciones que se producen con su entorno. Bajo este contexto, el desarrollo normal del lenguaje en los niños y niñas se va dando de forma progresiva y por diferentes etapas, las mismas deben cumplirse en ciertos periodos de tiempo y edad; es por ello la importancia del programa $\mathrm{CNH}$ para estimular el lenguaje dentro de este importante grupo social.

Palabras Claves: Creciendo con Nuestros Hijos, Desarrollo del lenguaje, Infantes, acciones educativas, desarrollo integral de niños y niñas. 


\begin{abstract}
Growing with Our Children - $\mathrm{CNH}$ is a social program promoted by the central government aimed at families of children between 0 and 36 months with the objective that this group of infants develop quality educational actions, that is to achieve a socio affective development, motor, intellectual, communication and language favoring an adequate state of health and nutrition. This activity is developed by educators and professional educators together with the support of families seeking to promote integral development from the earliest ages, through organizational forms and direction of all activities in order to encourage maximum stimulation of all the potentials of infants and ensure healthy growth. On the other hand, language is a gradual process in which the infant processes thanks to the continuous interactions that occur with their environment. In this context, the normal development of language in boys and girls is progressively taking place and, at different stages, they must be fulfilled in certain periods of time and age; that is why the importance of the $\mathrm{CNH}$ program to stimulate the language within this important social group.
\end{abstract}

Key Words: Growing with Our Children, Language development, Infants, educational actions, integral development of boys and girls. 


\section{Introducción.}

El gobierno central ecuatoriano durante los últimos años ha venido proporcionando ayuda al sector social, enfocándose en atender a niños, adolescentes, grupos y zonas vulnerables desprotegidas del país. A partir del año 2007 reformas institucionales y programas sociales han sido instituidos, tratando de crear un modelo de desarrollo socioeconómico incluyente, solidario, con sólidos principios humanistas (Salazar, 2016). Bajo este contexto, han sido innumerables los programas enfocados en nutrición, alimentación y de desarrollo infantil que han dado un giro a su enfoque inicialmente observado durante décadas pasadas, generándose entre estos programas sinergias y fusiones que han aprovechado las potencialidades de cada uno de los diferentes proyectos, eliminando la duplicidad de coberturas y optimizando recursos financieros, de infraestructura y de personal a fin de otorgar un mejor servicio a la población más necesitada.

Creciendo con Nuestros Hijos - CNH es una modalidad de atención alternativa, cuyo objetivo principal es alcanzar el desarrollo infantil integral. Educadoras y educadores familiares visitan a los padres para capacitarlos y promover el desarrollo de sus hijas e hijos en cada etapa del crecimiento. Para ello, utilizan tres estrategias: atención individual, atención grupal, participación familiar y comunitaria (Ministerio de Inclusión Económica y Social, 2018).

La estimulación del lenguaje, se refiere al desarrollo que experimenta el infante, es decir, la evolución del proceso del habla en los niños y niñas. El lenguaje constituye un proceso paulatino en el que el infante procesa gracias a las continuas interacciones que se producen con su entorno. Este aprendizaje empieza con las primeras percepciones que el bebé es capaz de realizar hasta familiarizarse con el mundo sonoro que le rodea. En dicho proceso el órgano del oído juega un papel relevante, de tal forma que, si la audición es buena, el niño será capaz de percibir su entorno y de 
asimilarlo, pero, si, por el contrario, presenta alguna pérdida de sensibilidad auditiva, el desarrollo del lenguaje podrá verse alterado e incluso interrumpido (Roca, 2013).

\section{Desarrollo}

\section{Desarrollo del lenguaje}

El desarrollo normal del lenguaje se va dando de forma progresiva y por diferentes etapas, las mismas deben cumplirse en ciertos periodos de tiempo y edad. Bajo este contexto, el lenguaje consta de cuatro aspectos: 1) semántico, 2) sintáctico, 3) fonológico y 4) pragmático (Barragán \& Lozano, 2011). El primer aspecto constituye el semántico mismo que se refiere a la comprensión del lenguaje, el sintáctico se refiere a las estructuras del lenguaje para formar enunciados y proposiciones, el fonológico se refiere a los fonemas o sonidos del habla y finalmente, el pragmático que constituye la utilización del lenguaje en un contexto adecuado en situaciones comunicativas (Cantwell \& Baker, 2013).

Los niños empiezan a combinar oraciones simples para constituir oraciones complejas en el periodo de 2 a 3 años de edad, el desarrollo de oraciones complejas se refiere a aspectos de aprendizaje de forma conectivas (sintácticas y estructuras sintácticas); contenido (relaciones semánticas entre proposiciones); y el uso (la cohesión del discurso) (Bloom, Lahey, Hood, Lifter, \& Fiess, 1991). 
Tabla 1. Desarrollo del lenguaje

\begin{tabular}{|c|c|c|}
\hline Etapas & Edad & Descripción \\
\hline Prelingüística & $\begin{array}{l}(0 \text { a } 1 \text { año } 6 \\
\text { meses límite })\end{array}$ & $\begin{array}{ll}\text { - } & \text { Comunicación mediante gestos, señas, ruidos. } \\
\text { - } & \text { Comprensión del lenguaje sencillo (con ayuda del contexto) } \\
\text { - } & \text { Intensión comunicativa. }\end{array}$ \\
\hline $\begin{array}{l}\text { Etapa de una } \\
\text { palabra }\end{array}$ & (1 a 2 años) & $\begin{array}{l}\text { - } \quad \text { Emisiones de una palabra (o aproximaciones) } \\
\text { - } \quad \text { comprensión del lenguaje sin necesidad de demasiadas pautas } \\
\text { - } \quad \text { Emisiones mono y bisilábicas } \\
\text { - } \quad \text { Articulación correcta de todas las vocales } \\
\text { - } 15 \text { meses (mínimo } 5 \text { palabras) } \\
\text { - } 18 \text { meses (mínimo } 8 \text { palabras) } \\
\text { - } 24 \text { meses (nombra en imágenes en dibujo (2) o señala (4)) }\end{array}$ \\
\hline $\begin{array}{l}\text { Lenguaje } \\
\text { telegráfico }\end{array}$ & $\begin{array}{l}(1 \text { año } 6 \text { meses } \\
\text { a } 2 \text { años } 6 \\
\text { meses })\end{array}$ & 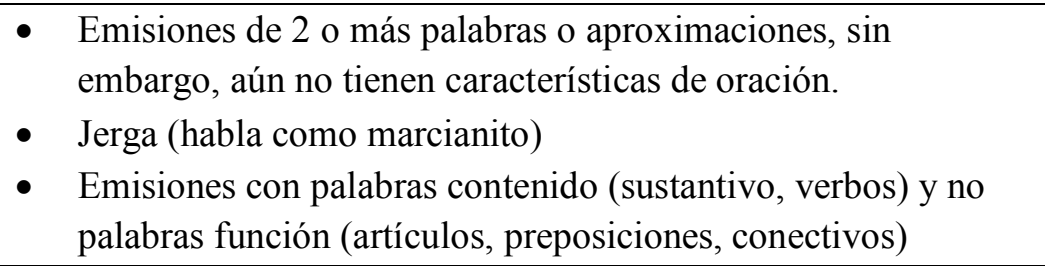 \\
\hline $\begin{array}{l}\text { Frases y oraciones } \\
\text { simples }\end{array}$ & $\begin{array}{l}(2 \text { años a } 3 \\
\text { años } 6 \text { meses) }\end{array}$ & $\begin{array}{l}\text { - Emisiones que se reconocen como frases u oraciones; resultan } \\
\text { breves y algunas aún dependen del contexto. } \\
\text { - Utilización de palabras contenido y función. } \\
\text { - Capacidad para iniciar, continuar, mantener y cambiar un } \\
\text { tema. } \\
\text { - Articula perfectamente } / \mathrm{d} /, / \mathrm{b} /, / \mathrm{m} /, / \mathrm{n} /, / \mathrm{k} /, / \mathrm{l} /, \mathrm{t} /, / 11 /, / \mathrm{p} /, / \mathrm{f} / \mathrm{y} \\
\text { diptongos } / \mathrm{ua} /, / \mathrm{ue} / \text {. }\end{array}$ \\
\hline $\begin{array}{l}\text { Oraciones } \\
\text { complejas }\end{array}$ & $\begin{array}{l}(3 \text { años a } 4 \\
\text { años } \\
\text { adelante })\end{array}$ & $\begin{array}{l}\text { - Comunicación bastante fluida con emisiones largas. } \\
\text { - Comprensión y uso de metáforas, chistes, absurdos. } \\
\text { - Relatos de eventos de manera coherente. }\end{array}$ \\
\hline \multirow{3}{*}{ Pronunciación } & $\begin{array}{l}\text { (4 años a } 4 \\
\text { años y medio) }\end{array}$ & - Articula perfectamente $/ \mathrm{j} /, / \mathrm{r} /, / \mathrm{g} /, / \mathrm{p} /, / \mathrm{b} /, / \mathrm{ie} /$ \\
\hline & (5 años) & $\begin{array}{l}\text { - Articula perfectamente los grupos /r/, /br/, /k1/, /gr/ y } \\
\text { diptongos } / \mathrm{au} /, / \mathrm{ei} / \mathrm{F}\end{array}$ \\
\hline & (6 años) & - Articula perfectamente /s/,/rr/, /pr/,/fr/, /tr/ y diptongo/eo/. \\
\hline
\end{tabular}

Fuente: Adaptado de Barragán \& Lozano (2011) “Identificación temprana de trastornos del lenguaje" 
El lenguaje verbal, escuchar, hablar, leer y escribir constituyen los desafíos céntricos en edades tempranas. En el mismo periodo que las niñas y niños se inician en el conocimiento y la comprensión del mundo (alfabetización cultural) resulta indispensable fortalecer las posibilidades de establecer vínculos con los otros, es decir, con adultos y pares a fin de aprender a confiar en las propias posibilidades de explorar, conocer, bailar, cantar, jugar, pintar, hablar con otros, resolver problemas habituales, sentirse querido y respetado, saberse capaz de ser cada vez más autónomo y permitirse expresar libremente (Di Caudo, 2012).

\section{Desarrollo infantil integral}

El desarrollo infantil integral constituye un proceso sistémico que busca garantizar las condiciones más adecuadas para los infantes, con el objetivo de proyectar mejores perspectivas y oportunidades en la calidad de vida. Por otro lado, las experiencias durante el desarrollo infantil integral marcan en gran medida el desarrollo del cerebro, y las destrezas, habilidades, capacidades, actitudes, emociones y en general conductas, se van moldeando a lo largo de estos primeros años de vida del niño o niña (Constante, Reinoso, Trávez, \& Defaz, 2016).

Promover el desarrollo integral desde las edades más tempranas supone indagar formas organizativas y de dirección de todas las actividades con el objetivo de propiciar estímulos al máximo de todas las potencialidades de los infantes y garantizar un sano crecimiento. Es por ello, que, si se necesitan diferentes tipos de propuestas educativas, todas ellas encaminadas a la interacción con objetos y otros seres humanos, que permitan la construcción de la identidad y la subjetividad, y el ejercicio e incremento de sus habilidades. (Ministerio de Inclusión Económica y Social, 2013). 
Bajo este contexto, el desarrollo infantil integral del niño o niña ecuatoriano se encuentra bajo el marco legal de la constitución y el Plan Nacional del Buen Vivir en los siguientes artículos y objetivos.

\section{Tabla 2. Marco Legal (desarrollo infantil integral)}

\begin{tabular}{|c|l|}
\hline $\begin{array}{c}\text { Plan Nacional del } \\
\text { Buen Vivir }\end{array}$ & $\begin{array}{l}\text { Objetivo 2: "Auspiciar la igualdad, la cohesión, la inclusión y la equidad } \\
\text { social y territorial en la diversidad" } \\
\text { Política 2.9: "Garantizar el desarrollo integral de la primera infancia, a } \\
\text { niñonas menores de 5 años" } \\
\text { Meta 2.6: "Universalizar la cobertura de programas de primera infancia } \\
\text { para niños/as menores de 5 años en situación de pobreza y alcanzar el 65\% } \\
\text { a nivel nacional" } \\
\text { Constitución }\end{array}$ \\
$\begin{array}{l}\text { Art. 44: "El Estado, la sociedad y la familia promoverán de forma } \\
\text { prioritaria el desarrollo integral de las niñas, niños y adolescentes, y } \\
\text { asegurarán el ejercicio pleno de sus derechos" }\end{array}$ \\
\hline
\end{tabular}

Fuente: Adaptado de la Asamblea Nacional (2011)

Programa Creciendo con Nuestros Hijos - CNH

La Modalidad Creciendo con Nuestros Hijos -CNH-, como servicio de atención familiar para la primera infancia, desarrolla un conjunto de estrategias integrales, no institucionalizadas, en zonas tanto urbanas como rurales. Este programa consiste en el trabajo con las familias de niñas y niños entre 0 a 3 años que no asisten aún a instituciones, se ejecuta a través de la acción de educadoras y educadores profesionales, con formación y capacitación especializada que organizan las actividades educativas en espacios comunitarios (Ministerio de Educación, 2016). 
Se basa en acciones de sensibilización y preparación, que realizan las Educadoras Familiares con las familias de niños y niñas de 0 a 36 meses de edad, para que éstas desarrollen acciones educativas de calidad, en su hogar y así lograr el desarrollo socio afectivo, motor, intelectual, de la comunicación y lenguaje favoreciendo un adecuado estado de salud y nutrición de sus hijos e hijas (Ministerio de Inclusión Económica y Social, 2013a).

Entre los objetivos principales que persigue el programa se encuentran: 1) Lograr el desarrollo máximo posible de las potencialidades tanto de niñas y niños menores de 0 a 36 meses en las siguientes áreas: intelectual, lenguaje, socio-afectivo y psicomotriz, 2) Preparar a las familias para que realicen acciones educativas estimulatorias para el desarrollo de sus hijos, brindándoles conocimientos nuevos en prácticas de crianza y vida familiar saludable y 3) Generar procesalmente niveles de cogestión comunitaria en las localidades, impulsando acciones de movilización social para lograr el ejercicio de los derechos de las niñas y niños menores de seis años (Organización de Estados Iberoamericanos, 2013).

La metodología que aplica este programa considera al niño como eje principal del proceso educativo, en donde, él o la educadora del INNFA-CNH es la orientadora de las actividades pedagógicas mientras que los padres y madres de familia son los ejecutores permanentes de las acciones educativas para lograr el desarrollo de sus hijos e hijas.

Para lograr los objetivos del Programa se manejan las siguientes estrategias: la modalidad se encuentra establecida a través de dos formas elementales: La atención individual y la atención grupal, las mismas que tienen como complemento las visitas de seguimiento domiciliario, actividad que ayuda a robustecer la ejecución de las actividades educativas planificadas en el hogar y sus 
posteriores resultados, así como, la ejecución de encuentros familiares y comunitarios que robustezcan la estrategia educativa diseñada (Ministerio de Inclusión Económica y Social, 2013).

Tabla 3. Estrategias aplicadas del Programa Creciendo con Nuestros Hijos - CNH

\begin{tabular}{|c|c|c|c|}
\hline \multirow{4}{*}{ Estrategias } & \multirow{4}{*}{$\begin{array}{l}\text { Educación } \\
\text { familiar }\end{array}$} & $\begin{array}{l}\text { Actividad } \\
\text { individual }\end{array}$ & $\begin{array}{l}\text { Se realiza con las niñas y niños de } 0 \text { a } 2 \text { años de } \\
\text { edad y sus familias. En este caso, se orientan las } \\
\text { actividades a la familia directamente en el hogar. } \\
\text { Normalmente esta actividad dura un tiempo } \\
\text { promedio de } 45 \text { minutos y es ejecutada una vez } \\
\text { por semana. }\end{array}$ \\
\hline & & Actividad grupal & $\begin{array}{l}\text { Se ejecuta con las niñas y niños de } 2 \text { a } 3 \text { años y } \\
\text { sus familias, los cuales se los organiza por grupos } \\
\text { de la misma edad (por año de vida). } \\
\text { Normalmente, esta actividad dura un tiempo } \\
\text { promedio de } 1 \text { h15 y es ejecutada una vez por } \\
\text { semana. }\end{array}$ \\
\hline & & $\begin{array}{l}\text { Seguimiento } \\
\text { domiciliario }\end{array}$ & $\begin{array}{l}\text { Esta actividad radica en visitas individuales por } \\
\text { él o la educadora a las familias involucradas en el } \\
\text { proyecto. Este seguimiento, le permite verificar si } \\
\text { en este caso el papá, la mamá, o a su vez la } \\
\text { persona responsable del desarrollo integral de la } \\
\text { niña o niño, se encuentra ejecutando las } \\
\text { actividades estimulatorias planificadas para los } \\
\text { diferentes domicilios. }\end{array}$ \\
\hline & & $\begin{array}{l}\text { Encuentros } \\
\text { familiares y } \\
\text { comunitarios }\end{array}$ & $\begin{array}{l}\text { Representan momentos de encuentro de las } \\
\text { familias involucradas en el proyecto tanto de } \\
\text { atención individual como de atención grupal y de } \\
\text { la comunidad. Esta actividad es ejecutada de } \\
\text { forma mensual y cuya finalidad es contribuir a } \\
\text { robustecer la preparación que han alcanzado las } \\
\text { diferentes familias implicadas, así como para } \\
\text { ampliar sus experiencias recreativas y culturales. } \\
\text { Entre las principales actividades a desarrollar se } \\
\text { puede citar los siguientes: encuentros deportivos, } \\
\text { talleres de capacitación, paseos, fiestas, etc. }\end{array}$ \\
\hline
\end{tabular}

Fuente: Adaptado de la Organización de Estados Americanos (2013) "Programa Creciendo con Nuestros Hijos - CNH', 
Modelo de atención Creciendo con Nuestros Hijos - CNH

El modelo de atención para el programa Creciendo con Nuestros Hijos - CNH se encuentra estructurado de la siguiente manera:

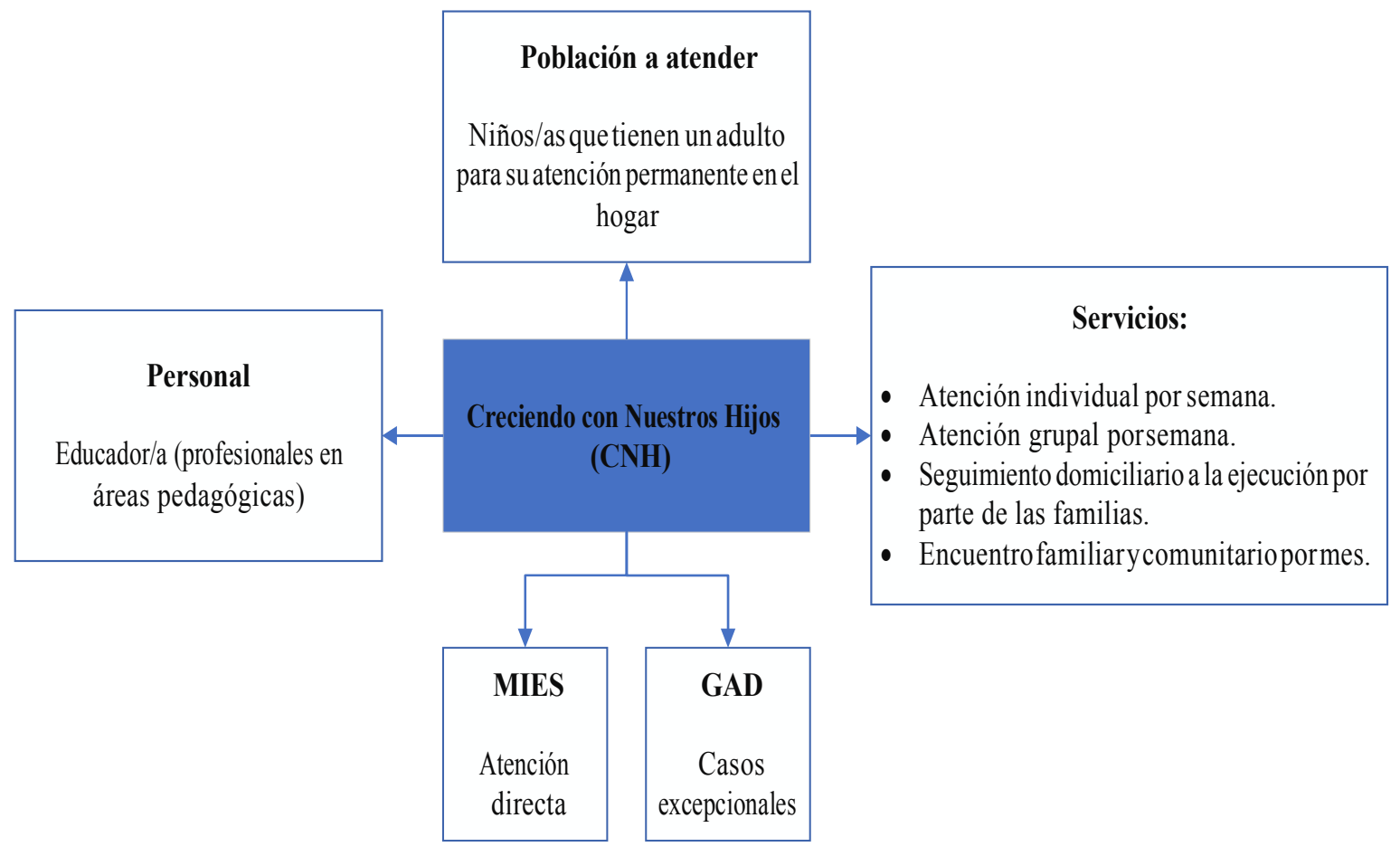

Figura 1. Modelo de atención Creciendo con Nuestros Hijos

Fuente: Adaptado del Ministerio de Inclusión Económica y Social (2013) "Modelo de gestión de Desarrollo Infantil Integral"

Creciendo con Nuestros Hijos es un servicio de atención directa, en casos excepcionales se ha llegado a acuerdos para la ejecución de convenios con los diferentes GADS; cuenta con una metodología basada en la participación activa de las familias, la comunidad y la articulación intersectorial, para la promoción del desarrollo integral de las niñas y niños del país (Ministerio de Inclusión Económica y Social, 2013a). 
Entre los logros y resultados que ha conseguido el programa Creciendo con Nuestros Hijos $\mathrm{CNH}$ se destaca el incremento de la cobertura, el incremento en la calidad y el fortalecimiento de la intersectorialidad. Bajo este contexto, a continuación, dentro de la tabla se presenta información resumida acerca de los logros y resultados obtenidos.

Tabla 4. Logros y resultados del Programa Creciendo con Nuestros Hijos - CNH

\begin{tabular}{|c|c|}
\hline Logros & Resultados \\
\hline $\begin{array}{l}\text { Incremento de la } \\
\text { cobertura }\end{array}$ & $\begin{array}{l}\text { - El programa Creciendo con Nuestros Hijos - CNH asegura el } 68 \% \text { de } \\
\text { la cobertura total de los servicios de desarrollo infantil integral. } \\
\text { - De } 1.123 \text { parroquias que constan en el mapa de pobreza, el programa } \\
\text { Creciendo con Nuestro Hijos - CNH interviene en } 917 \text {. }\end{array}$ \\
\hline Incremento de la calidad & $\begin{array}{l}\text { - } \\
\text { - } \quad \text { Increma técnica con estándares de calidad. } \\
\text { programa Creciendo con Nuestros Hijos - CNH. } \\
\text { - Profesionalización de los y las educadoras del programa Creciendo } \\
\text { con Nuestros Hijos - CNH. }\end{array}$ \\
\hline $\begin{array}{l}\text { Fortalecimiento de la } \\
\text { intersectorialidad }\end{array}$ & $\begin{array}{l}\text { - Control de salud para el } 91 \% \text { de las niñas y niños cubiertos por el } \\
\text { programa Creciendo con Nuestros Hijos - CNH. }\end{array}$ \\
\hline
\end{tabular}

Fuente: Adaptado de Ministerio Coordinador de Desarrollo Social (2014) "Infancia plena de 0 a 5 años, su futuro es hoy"

\section{Conclusiones.}

Durante los últimos años, el gobierno central a impulsado proyectos sociales con el objetivo de ayudar a los grupos más vulnerables, en este caso Creciendo con Nuestros Hijos es un proyecto enfocado en atender a niños y niñas en edades de entre 0 a 36 meses a través de educadores 
profesionales quienes aplican estrategias enfocadas en atención individual, atención grupal, participación familiar y comunitaria.

La actividad individual es ejecutada con niñas y niños de 0 a 24 meses de edad y sus familias, en donde, las actividades son realizadas a la familia directamente en el hogar. Por otro lado, la actividad grupal, se enfoca en infantes de 24 a 36 meses y sus familias, los cuales se los organiza por grupos de la misma edad. El seguimiento domiciliario permite verificar si en este caso el papá, la mamá, o a su vez la persona responsable del desarrollo integral de la niña o niño, se encuentra ejecutando las actividades estimulatorias planificadas. Finalmente, los encuentros familiares y comunitarios son momentos de encuentro de las familias involucradas en el proyecto tanto de atención individual como de atención grupal y de la comunidad.

El lenguaje en los infantes se va desarrollando de forma paulatina y por diferentes etapas, las mismas que deben cumplirse en ciertos periodos de tiempo y edad. El primer aspecto a desarrollar es el semántico, el cual se enfoca en la comprensión del lenguaje, posterior a ello, se encuentra el sintáctico que se refiere a las estructuras del lenguaje para formar enunciados y proposiciones, el aspecto fonológico se enfoca en los fonemas o sonidos del habla y finalmente, el aspecto pragmático consiste en la utilización del lenguaje en un contexto adecuado en situaciones comunicativas.

Se identifican seis etapas para el desarrollo del lenguaje: prelingüística, en edades de entre 0 a 1 año 6 meses en la cual la comunicación se da a través de gestos, señas y ruidos, etapa de una palabra, en edades de 1 a 2 años que constituye la emisión de una palabra o sus aproximaciones, lenguaje telegráfico, en edades de 1 año 6 meses a 2 años 6 meses, en la cual la comunicación se extiende a la emisión de palabras contenido, es decir sustantivo, verbo. La etapa de frases y oraciones simples, comprende edades de entre 2 años a 3 años 6 meses, en donde se da emisiones de 
frases u oraciones, la etapa de oraciones complejas, en edades de 3 años a 4 años en adelante tiene como principal característica una comunicación bastante fluida con emisiones largas.

\section{Referencias bibliográficas.}

Asamblea Nacional. (2011). Constitucion de la República del Ecuador 2008 (pp. 1-136). Quito.

Barragán, E., \& Lozano, S. (2011). Identificación temprana de trastornos del lenguaje. Revista Médica Clínica Las Condes, 22(2), 227-232. https://doi.org/10.1016/S0716-8640(11)70417-5

Bloom, L., Lahey, M., Hood, L., Lifter, K., \& Fiess, K. (1991). Complex sentences : Acquisition of syntactic connectives and the semantic relations they encode. Teachers College, Columbia University, 5(1980), 1-21.

Cantwell, D., \& Baker, L. (2013). The language environment of autistic and dysphasic children, 17(4), 604-613. https://doi.org/10.1016/S0002-7138(09)61014-1

Constante, M., Reinoso, R., Trávez, J., \& Defaz, Y. (2016). La estimulación mediante el uso de productos tecnológicos en el desarrollo integral en los niños y niñas de 1 a 3 años. UTCiencia, 3(3), 154-165. https://doi.org/1390-6909

Di Caudo, M. V. (2012). Hablar de niñez no es hablar de pequeñeses: algunos desafíos para la política pública del Nivel Inicial en la Región de América Latina. Revista de Educación Alteridad, 7(2), 106-115.

Ministerio de Inclusión Económica y Social. (15 de Mayo de 2018). 176 infantes egresas de programa CNH. Obtenido de 176 infantes egresas de programa CNH: https://www.inclusion.gob.ec/176-infantes-egresan-de-programa-cnh/

Ministerio Coordinador de Desarrollo Social. (2014). Infancia plena de 0 a 5 su futuro es hoy (pp. 1-12). Quito. 
Ministerio de Educación. (2016). Servicio de atención familiar para la primera infancia modalidad de educación inicial con familias- Guía técnico operativa. (Ministerio de Educación del Ecuador, Ed.) (pp. 1-160). Quito.

Ministerio de Inclusión Económica y Social. (2013a). Modelo de gestión de desarrollo infantil integral (pp. 1-32). Quito.

Ministerio de Inclusión Económica y Social. (2013b). Política Pública Desarrollo Infantil Integral (pp. 1-120). Quito.

Organización de Estados Iberoamericanos. (16 de Julio de 2013). Educación Inicial. Obtenido de Programa Creciendo con Nuestros Hijos - $\mathrm{CNH}$ https://www.oei.es/historico/linea3/inicial/ecuadorne.htm

Roca Melchor, E. (2013). La estimulación del lenguaje en educación infantil: un programa de intervención en el segundo ciclo de educación infantil. Universidad de Valladolid.

Salazar Marroquín, S. (2016). Programas sociales de alimentación y nutrición del Estado ecuatoriano, estrategia nacional en favor de la alimentación saludable. Revista Economía, $X L I(41), 76-96$. 